\title{
Integral State Feedback Control Using Linear Quadratic Gaussian in DC-drive System
}

\author{
Supriyanto Praptodiyono a, Hari Maghfiroh ${ }^{\text {b, * }}$, Joko Slamet Saputro b, \\ Agus Ramelan ${ }^{b}$ \\ ${ }^{a}$ Department of Electrical Engineering \\ Universitas Sultan Ageng Tirtayasa (UNTIRTA) \\ Jl. Jendral Sudirman Km.3, Kotabumi \\ Cilegon, Indonesia \\ ${ }^{b}$ Department of Electrical Engineering \\ Universitas Sebelas Maret (UNS) \\ Jl. Ir. Sutami 36A, Jebres \\ Surakarta, Indonesia
}

\begin{abstract}
The electric motor is one of the technological developments which can support the production process. DC motor has some advantages compared to AC motor especially on the easier way to control its speed or position as well as its widely adjustable range. The main issue in the DC motor is controlling the angular speed with uncertainty and disturbance. The alternative solution of a control method with simple, easy to design, and implementable in a multi-input multi-output system is integral state feedback such as linear quadratic Gaussian (LQG). It is a combination between linear quadratic regulator and Kalman filter. One of the advantages of this method is the usage of fewer sensors compared with the original linear quadratic regulator method which uses sensors as many as the state in the system model. The design, simulation, and experimental study of the application of LQG as state feedback control in a DC-drive system have been done. Both performance and energy were analyzed and compared with conventional proportional integral derivative (PID). The gain of LQG was determined by trial whereas the PID gain is determined from MATLAB autotuning without fine-tuning. The load test and tracking test were carried out in the experiment. Both simulation and hardware tests showed the same result which LQG is superior in integral absolute error (IAE) by up to $74.37 \%$ in loading test compared to PID. On the other side, LQG needs more energy, it consumes higher energy by $6.34 \%$ in the load test.
\end{abstract}

Keywords: DC motor, speed control, integral state feedback, LQG.

\section{INTRODUCTION}

The electric motor is one of the technological developments which can support the production process. The development is not only in the manufacturing but also in the transportation sector. Based on its supply current, there are two types of the electric motor which are $\mathrm{AC}$ motor and DC motor. The DC motor has some advantages compared to the AC motor on its easier way to control the speed or position and also wide adjustable range [1]-[2]. However, it also has some issues such as the usage of a mechanical commutator (brush) which causes high maintenance costs [3]. Generally, the DC motors are used in electric trains steel, rolling mills, robotics actuators, and electric vehicles [4].

The controlling speed of the DC motor is generally conducted by changing its terminal voltage [5]. The main issue in DC motor is controlling the angular speed with uncertainty and disturbance [6]. There is a lot of control method proposed on controlling the speed of DC motors such as proportional integral derivative (PID) [5], linear quadratic regulator (LQR) [7], sliding mode control

\footnotetext{
* Corresponding Author.

Email: hari.maghfiroh@staff.uns.ac.id

Received: April 5, 2021 ; Revised: September 14, 2021

Accepted: September 28, 2021 ; Published: December 31, 2021

Open access under CC-BY-NC-SA

(C) 2021 PPET - LIPI
}

(SMC) [8], integral state feedback [9], and linear quadratic Gaussian (LQG) [10].

PID is a control method that is often used for DC motor control because it has simple and easy to implement in real hardware [11], [12]. However, the PID control has a constraint that is a sudden change in parameter variation, making the PID controller give a bad response [13]. The alternative solution of a control method with simple, easy to design, and implementable in a multi-input multi-output system is integral state feedback [9], [14].

There are some methods to implement integral state feedback control. One of them is LQG. According to [15] this method can minimize estimation errors and produce optimal control signals. The LQG control is the combination of LQR control with the Kalman Filter which works as an optimal estimation so that new measurements can be directly processed and reduce the estimated mean square error.

In this study, the application of LQG as the integral state feedback control method will be used to control the speed of a DC motor. The performance and energy consumption will be analyzed. Experiments and tests were carried out both in simulation and real hardware. The proposed algorithm was tested in a mini conveyor driven by a DC motor. The PID algorithm is also used as a comparison. 
The contribution of this paper is proposing the implementation of LQG control in the DC-drive system. The advantages of this method are on the usage of fewer sensors compared with the original LQR method which uses sensors as many as the state in the system model. The novelty of this article is analyzing both performance and control energy used which most of the researchers only consent to the first parameter.

The rest of this paper presents the material and method in Section II including system modelling and LQG control design. The experimental result will be discussed in Section III. Finally, the conclusion is provided in the last section.

\section{MATERIAL AND MeThOD}

\section{A. Mini Conveyor Model}

Figure 1 shows block diagram of the mini conveyor system used in this research. The DC motor with buildin encoder specification is resumed in Table 1 . The motor driver module is L298N. The Arduino Uno controls and communicates to the $\mathrm{PC}$ to send the data via serial communication. There are also current and voltage sensors which are ACS712 and voltage divider, respectively. The current and voltage data are required to calculate the power and energy consumption.

Generally, the system model can be constructed based on mathematical equations or modeling based on input-output data of the system. The second method is also known as black-box modeling [16]. Some researchers use the first method (mathematically based) to get the system model such as in [17]-[20]. On the other hand, [15] and [10] use the second method by taking data from the input-output of the system to find the system model. In the first method, system parameters are required; therefore, it is not suitable for hardware implementation where no parameters of the system are

TABLE 1

DC MOTOR SPECIFICATIONS

\begin{tabular}{cc}
\hline Parameters & Value \\
\hline Rated voltage $(\mathrm{V})$ & 12 \\
Rated current $(\mathrm{A})$ & 5.5 \\
Max speed $(\mathrm{rpm})$ & 250 \\
Max torque $(\mathrm{kg} / \mathrm{cm})$ & 10.6 \\
\hline
\end{tabular}

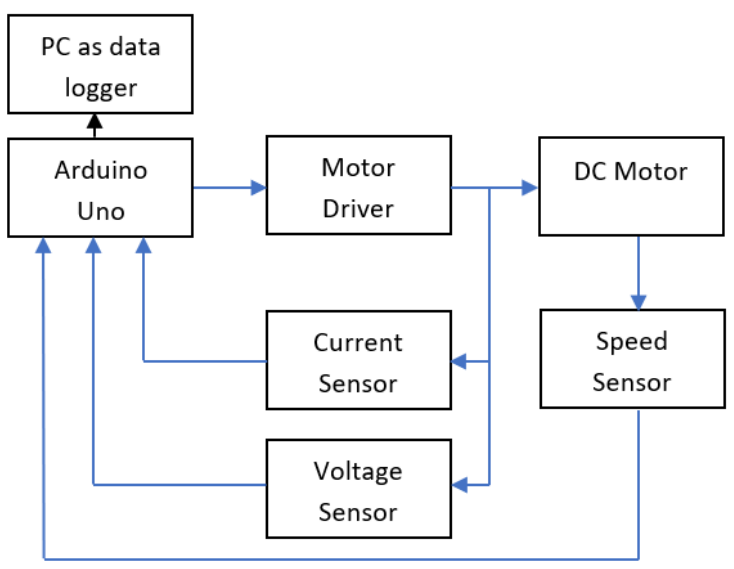

Figure 1. Block Diagram of the Mini Conveyor System. ready. The second method of modeling is chosen in this research.

Both the input signal to the system which is voltage and the output signal which is speed are collected with the sampling time of $0.335 \mathrm{~s}$. This data is used to find the system model using MATLAB System Identification. Equation (1) is the state space model of the system in second order form. This model is completely controllable and observable. Prior to implementation in the real hardware system, the control algorithm is tested in MATLAB/Simulink.

$$
\begin{gathered}
\dot{x}=\left[\begin{array}{cc}
0.91 & 0.04 \\
1 & 0
\end{array}\right] x+\left[\begin{array}{l}
1 \\
0
\end{array}\right] u \\
y=\left[\begin{array}{ll}
1 & 0
\end{array}\right] x
\end{gathered}
$$

\section{B. LQG Control Design}

LQG control is one type of optimal control. It is the combination between LQR and Kalman Filter [21]. The LQG solves the weakness of LQR control which requires the number of sensors as the number of states and replaces them with an observer, Kalman Filter [22]. This is very useful since not all the states of the system can be measured. Replacing the sensors with an observer also reduces the cost of the system. However, it does not guarantee the robustness of the system against uncertainties in the operating conditions [23].

The block diagram of LQG control that includes the LQR dan Kalman Filter is shown in Figure 2. In the system, the Kalman filter is used to estimate the state of the system. The estimated state is sent to LQR control as a state feedback. Kalman Filter needs a system model to estimate the state of the system.

Kalman Filter is a state estimation model that can estimate state variables from the measurement which has noise. If the noise is of Gaussian type, then the error variation can be optimally minimized [15]. The process estimation is conducted by using a form of feedback control that can be in the form of noise measurement. The equation for the Kalman filter also uses the Riccati equation as in (2), (3). This is because optimal control and optimal estimation are dualities, such as control and observation so that the Kalman filter has the same form equation as LQR (4), (5). Where $K_{L Q R}$ and $K_{f}$ are LQR gain dan observer gain, respectively. $Q$ and $R$ are the weight of the state and the weight for control input, respectively, which are used in LQR, whereas $V d$ and $V n$ are disturbance covariance and noise covariance, respectively used in Kalman Filter.

$$
K_{f}=\left(V_{n}+C P C^{T}\right)^{-1} C P A^{T}
$$

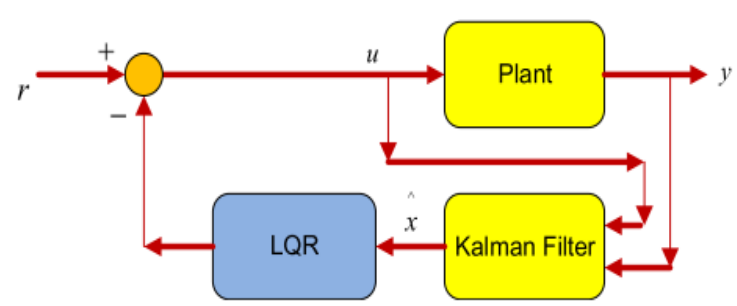

Figure 2. LQG: Combination of LQR and Kalman Filter [12]. 


$$
\begin{gathered}
P_{e}=A P_{e} A^{T}-\left(A P_{e} C^{T}\right)\left(V_{n}+C P_{e} C^{T}\right)^{-1}\left(C P_{e} A^{T}\right)+V d \\
K_{l q r}=\left(R+B^{T} P B\right)^{-1} B^{T} P A \\
P=A^{T} P A-\left(A^{T} P B\right)\left(R+B^{T} P B\right)^{-1}\left(B^{T} P A\right)+Q
\end{gathered}
$$

The LQG control design process is shown in Figure 3. Whereas $K_{L Q R}$ dan $K_{f}$ are calculated using MATLAB with the command as shown in Figure 4. Where matrix $Q$ and $R$ are chosen by trial and $V n$ and $V d$ are assumed to be 0.01 and $0.01 I$, where $I$ is the identity matrix.

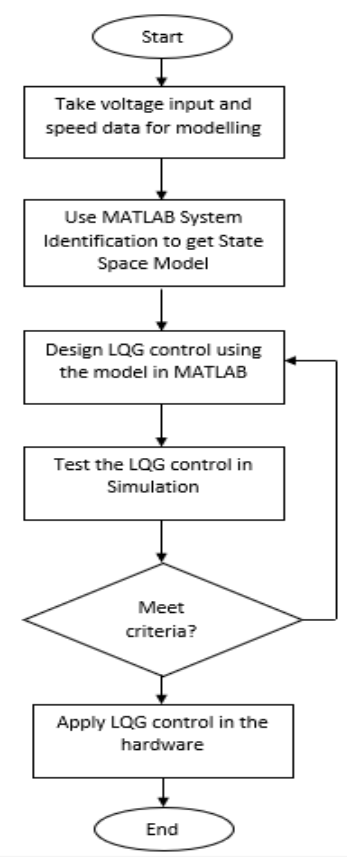

Figure 3. LQG Control Design Process.

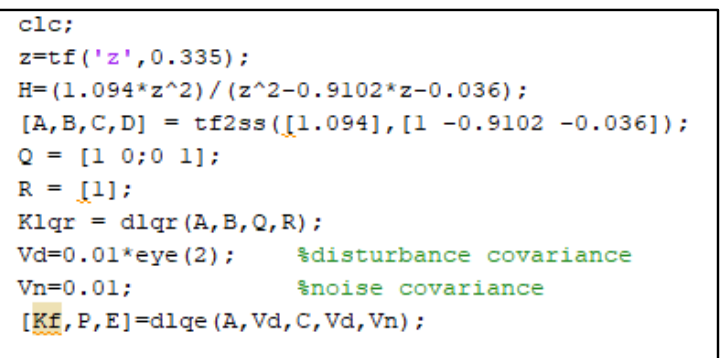

Figure 4. MATLAB Command for LQR Gain and Kalman Filter Gain.

\section{Result AND Discussion}

Both simulation and the experimental test were carried out to prove the performance of LQG control in the DC-drive system. Classical PID control is used to compare the result of the proposed integral state feedback control. In the hardware test, there are two test conditions which are load test and speed tracking test. The control tolerance for the test is $\pm 2 \%$.

\section{A. Simulation Test}

The simulation test was done in the MATLAB Simulink environment. The block diagram shown in Figure 5 is the control system. The dashed rectangle is for PID and another one is with the LQG control method. The state space model of the system is used to tune the controller in simulation. PID tuning is done with MATLAB autotuning without fine-tuning. Whereas, for LQG, tuning is done using (2)-(5). The tuning is used to find estimator gain, feedback gain, and integrator gain. In this simulation, the white noise is added to know the controller performance against the white noise.

Figure 6 shows the result of the simulation test. In this test, step responses, tracking, and disturbance tests are resumed in one simulation time. The speed profile is

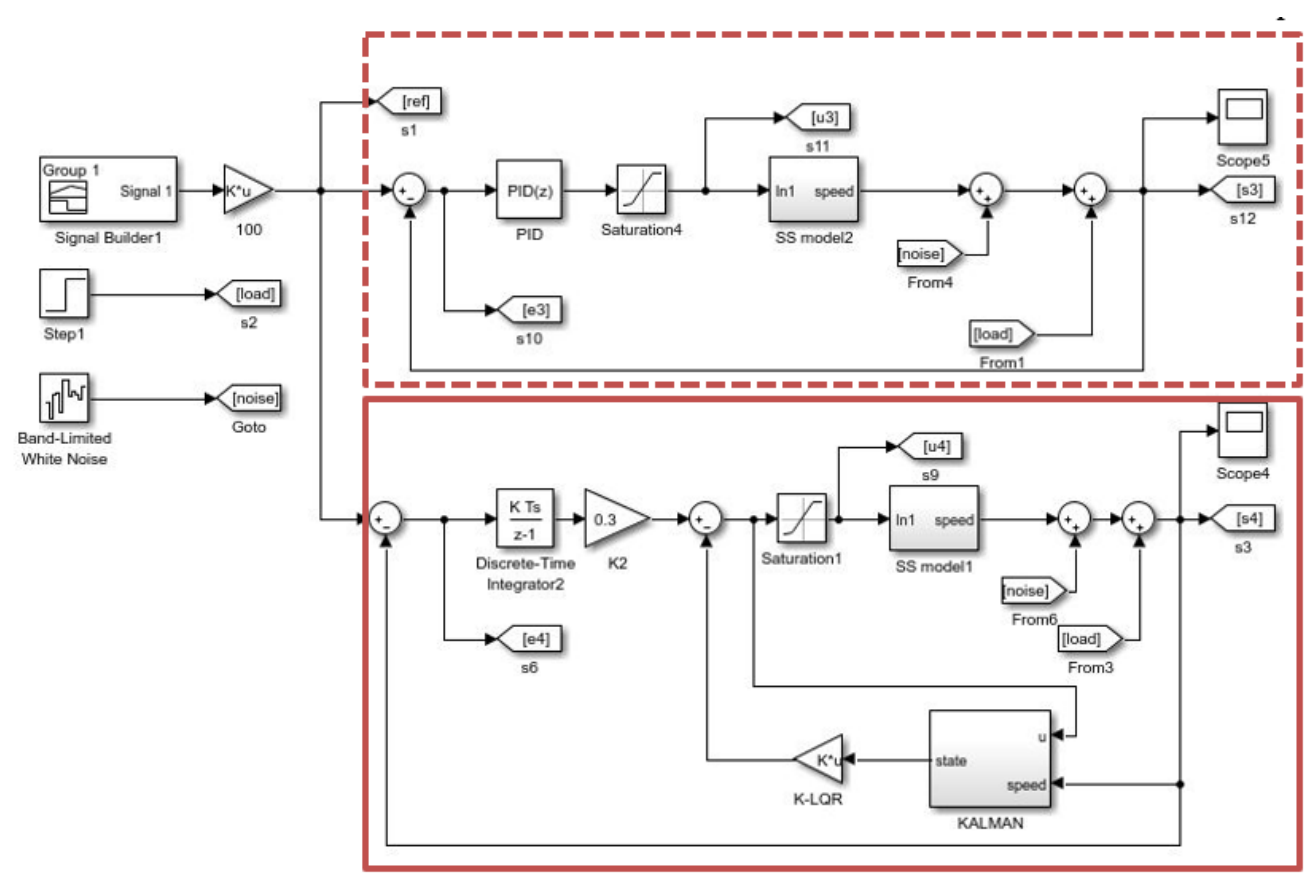

Figure 5. Block Diagram of PID and LQG Control in Simulink. 


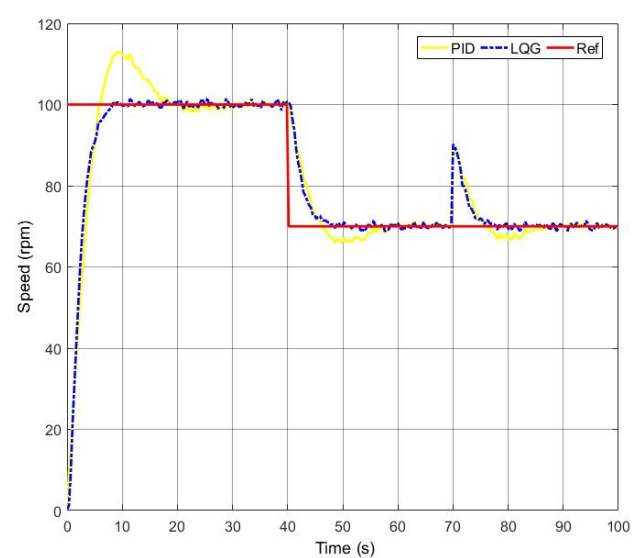

(a)

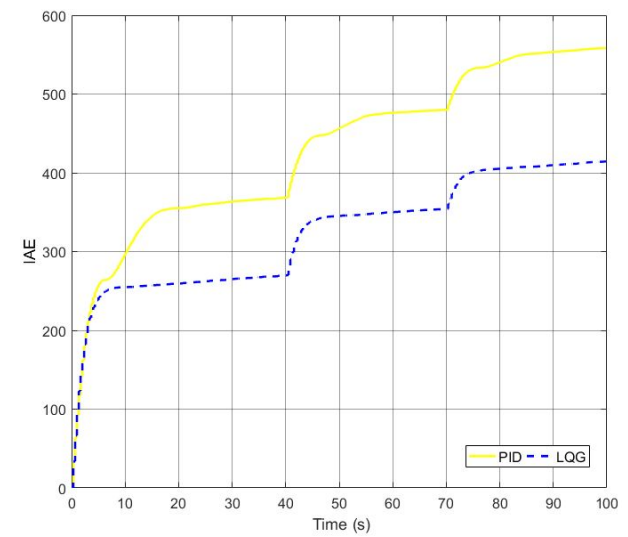

(b)

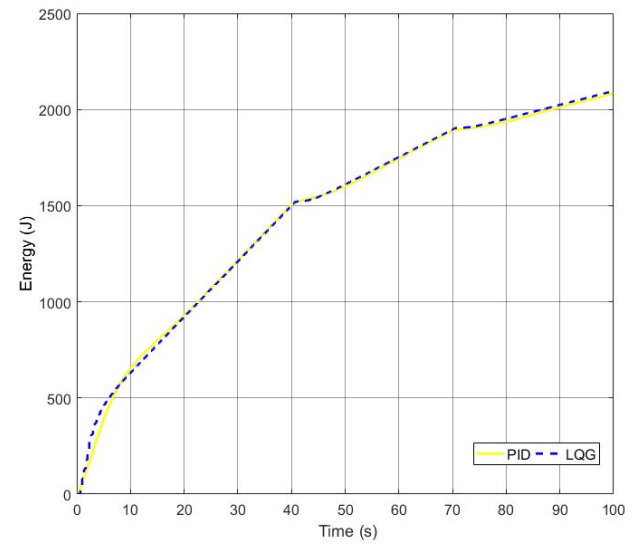

(c)

Figure 6. System Responses in Simulation Test, (a) Speed Profile,

(b) IAE Profile, (c) Integral of Square of Control Effort Profile.

shown in Figure 6(a). It informs that for step responses with set-point $100 \mathrm{rpm}, \mathrm{LQG}$ is superior to PID since it reaches the set-point faster and without overshoot (OS). On the other hand, the PID response has a high overshoot and takes twice as much time as LQG in settling time. At time 40, the speed is decreased to $70 \mathrm{rpm}$. LQG can follow the speed changes faster and without undershooting (US) compared to PID. At time 70, a disturbance signal with an amplitude of 20 is added. The control responses are increasing. LQG can maintain system response well and come back to the set-point fast without undershooting. On the other hand, there is an undershoot in PID control.
TABLE 2

RESUlt OF Simulation Test

\begin{tabular}{cccccc}
\hline $\begin{array}{c}\text { Control } \\
\text { Algorithm }\end{array}$ & $\begin{array}{c}\text { Settling } \\
\text { Time (s) }\end{array}$ & \% OS & \%US & IAE & $\boldsymbol{f U}^{2} \boldsymbol{d t}$ \\
\hline PID & 16.41 & 13 & 7.14 & 558.29 & 2082.9 \\
LQG & 7.37 & 0 & 0 & 414.38 & 2096.1 \\
\hline
\end{tabular}

Figure 6(b) and Figure 6(c) inform the integral of absolute error (IAE) and control effort of the system, respectively. IAE is used as an indicator of control performance while control effort is an indicator for control energy. The IAE profile shows that the LQG method has a lower IAE than PID. On the other side, the control effort profile shows that LQG has higher energy. The detailed result of the simulation test is resumed in Table 2. LQG has lower IAE and higher energy by 25.78 $\%$ and $0.6 \%$, respectively, compared to PID.

\section{B. Load Test}

This test was performed experimentally using a mini conveyor. In this test, the step responses and load test are analyzed. The load with a mass of $617 \mathrm{gr}$ was added at a time of $75 \mathrm{~s}$. Figure 7 shows the load test result including speed, IAE, and energy profile. In the simulation test, since it uses a system model in the form of the state space, the control energy is taken from the control effort. Whereas, in hardware testing, the energy is measured using voltage and current sensors. The DC power is calculated by the multiplication of voltage and current. While the energy is from the integration of the power.

Figure 7(a) is the speed profile. It shows that LQG response is as faster as the simulation result with only 2 $\mathrm{s}$ differences. On the other side, the PID response with the same algorithm in simulation and hardware gives different responses. For example, in settling time with the same set-point, the real hardware result gives three-time slower responses. Both control method has no overshoot since the tolerance is $\pm 2 \%$. When the load has been added the speed of each controller is decreasing but is still in the tolerance range.

From the performance point of view, LQG has a much lower IAE compared to PID by $74.37 \%$ as shown in Figure 7(b). While in the energy point of view, LQG has higher energy by $6.34 \%$ as shown in Figure 7(c). This result is the same as the simulation test result where LQG is superior in IAE with higher control energy. Detailed results are listed in Table 3.

\section{Tracking Test}

The last test is the tracking test which is speed changes. The first set-point speed is $100 \mathrm{rpm}$ and increased to $140 \mathrm{rpm}$ at $100 \mathrm{~s}$. The result of the test is depicted in Figure 8. The speed profile, Figure 8(a), informs that in the first set-point, it has the same result as the load test since it has the same set-point value.

TABEL 3

RESULT OF TRACKING TEST

\begin{tabular}{ccccc}
\hline $\begin{array}{c}\text { Control } \\
\text { Algorithm }\end{array}$ & $\begin{array}{c}\text { Settling } \\
\text { Time (s) }\end{array}$ & \% OS & IAE & Energy (J) \\
\hline PID & 55 & 1.4 & 6425 & 758.5 \\
LQG & 7 & 0 & 2014 & 845.2 \\
\hline
\end{tabular}




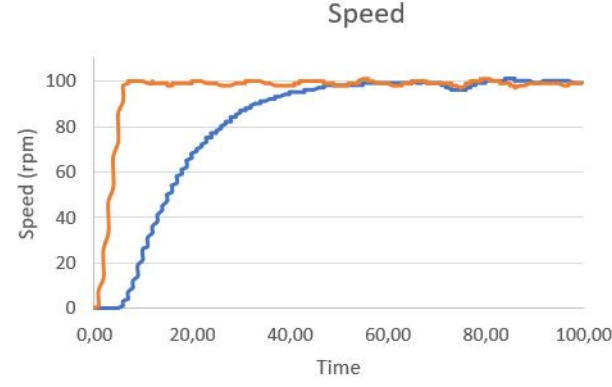

(a)

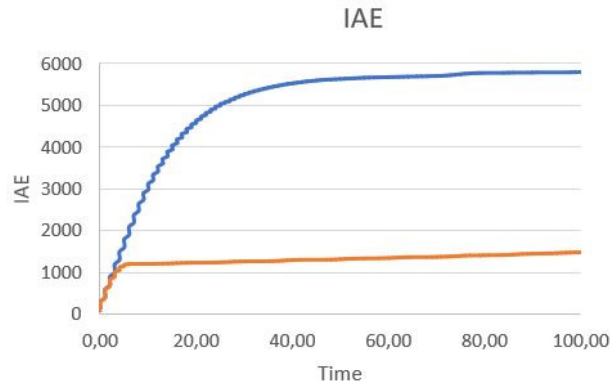

(b)

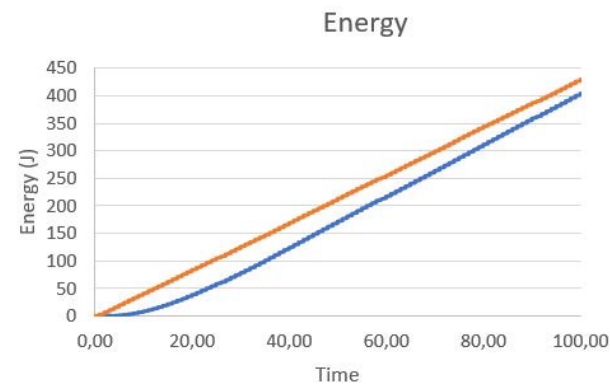

(c)

Figure 7. System Responses in Load Test, (a) Speed Profile, (b) IAE Profile, (c) Energy Profile.

Whereas in the second set-point, PID can track the setpoint faster compared with the first set-point. However, LQG is still faster. The overshoot of both methods is under-tolerance.

The IAE and energy curve increased significantly when the speed set-point increased. The final IAE value shows that LQG still has a lower value compared to PID by $68.65 \%$. On the other hand, LQG has higher control energy by $11.43 \%$ because it is used to get faster responses. The result of the tracking test is resumed in Table 4.

\section{CONCLUSION}

The design, simulation, and experimental study of the application of LQG as state feedback control in a DCdrive system have been performed. Both performance and energy are analyzed and compared with conventional PID. The gain of LQG is determined by trial whereas the PID gain is determined from MATLAB autotuning without fine-tuning. The load test and tracking test were carried out in the experiment. Both simulation and hardware tests show the same result which LQG is superior in IAE by up to $74.37 \%$ in loading test compared to PID. On the other side, LQG needs more
TABEL 4

RESULT OF TRACKING TEST

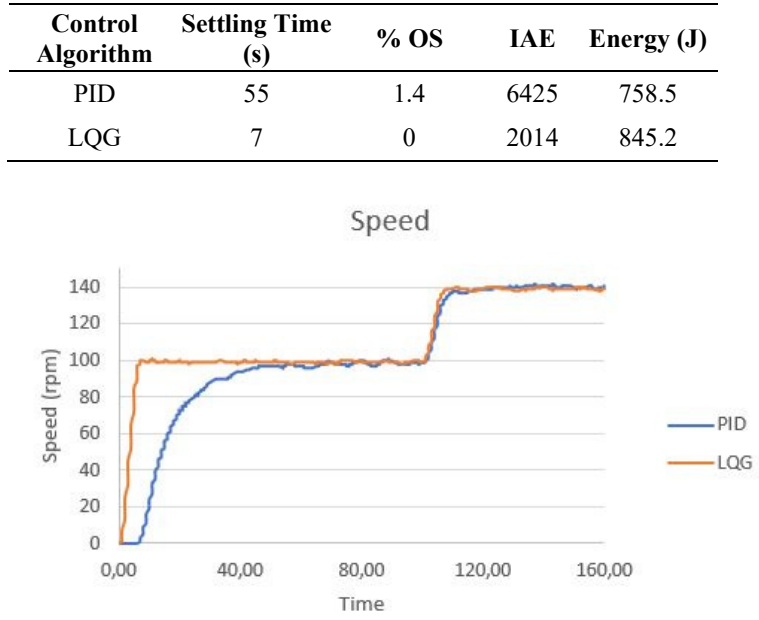

(a)

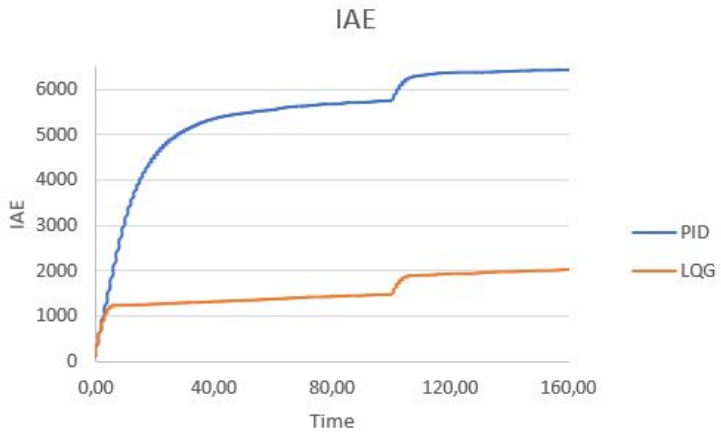

(b)

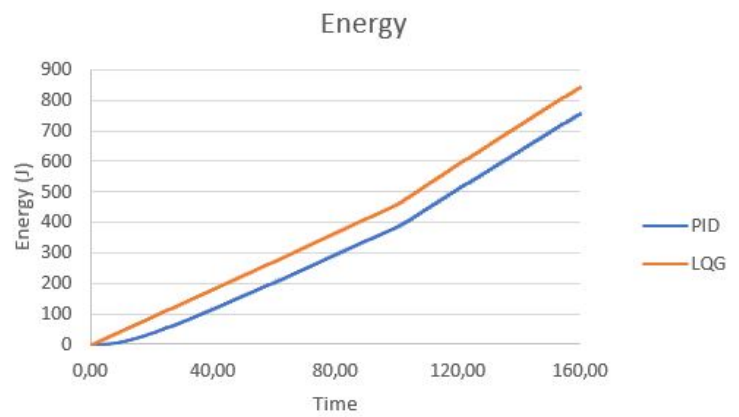

(c)

Figure 8. System Responses in Tracking Test, (a) Speed Profile,

(b) IAE Profile, (c) Energy Profile.

energy, it consumes higher energy by $6.34 \%$ in the load test. The other important result is LQG has nearly the same result in both simulation and real hardware, while PID does not. PID still needs to fine-tune. The drawback of the LQG is it needs a system model to build an estimator. However, it can be solved using black-box modeling.

\section{ACKNOWLEDGMENT}

This research is the collaboration between Sultan Ageng Tirtayasa University (UNTIRTA) and Sebelas Maret University (UNS). 


\section{REFERENCES}

[1] A. Faramarzi and K. Sabahi, "Recurrent fuzzy neural network for DC-motor control," in 2011 Fifth Int. Conf. Genet. Evol. Comput., 2011, pp. 93-96, doi: 10.1109/ICGEC.2011.31.

[2] U. K. Bansal and R. Narvey, "Speed control of DC motor using fuzzy PID controller," Adv. Electron. Electr. Eng., vol. 3, no. 9, pp. 1209-1220, 2013.

[3] C. A. Kumar, B. R. Harijan, M. K. Kumar, and M. Bharathi, "BLDC motor speed control using fuzzy logic PID controller and comparing it with PI controller," Int. J. Eng. Adv. Technol., vol. 9, no. 2, pp. 4917-4922, 2019, doi: 10.35940/ijeat.B4962.129219.

[4] A. Hughes and B. Drury, Electric Motor and Drives: Fundamental, Types and Applications, 5th ed. Newnes, 2019.

[5] S. N. Al-Bargothi, G. M. Qaryouti, and Q. M. Jaber, "Speed control of DC motor using conventional and adaptive PID controllers," Indonesian J. Electr. Eng. Comput. Sci., vol. 16, no. 3, pp. 1221-1228, 2019, doi: 10.11591/ijeecs.v16.i3.pp12211228 .

[6] S. Zhang, W. Gu, Y. Hu, J. Du, and H. Chen, "Angular speed control of brushed DC motor using nonlinear method: Design and experiment," in $201635^{\text {th }}$ Chinese Control Conf., pp. 1045-1050, 2016, doi: 10.1109/ChiCC.2016.7553225.

[7] H. Maghfiroh, M. Gunawan, and M. Anwar, "Optimal energy control of DC-drive conveyor using LQR method," in American Institute Physics Conf. Proc., 2020, vol. 2217, no. 1, doi: 10.1063/5.0000619.

[8] E. H. Dursun and A. Durdu, "Speed control of a DC motor with variable load using sliding mode control," Int. J. Comput. Electr. Eng., 2020, vol. 8, no. 3, pp. 219-226, Jun. 2016, doi 10.17706/ijcee.2016.8.3.219-226.

[9] A. Ma'arif and N. R. Setiawan, "Control of DC motor using integral state feedback and comparison with PID: Simulation and arduino implementation," J. Robot. Control, vol. 2, no. 5, pp. 456-461, 2021, doi: 10.18196/jrc. 25122.

[10] E. I. Ajiprasetyo, A. Rusdinar, and P. D. Wibawa, "Design and implementation control LQG for DC motor velocity," $e$ Proceeding Eng., vol. 2, no. 2, Aug. 2015, pp. 2018-2025.

[11] D. Somwanshi, M. Bundele, G. Kumar, and G. Parashar, "Comparison of fuzzy-PID and PID controller for speed control of DC motor using LabVIEW," Procedia Comput. Sci., vol. 152, pp. 252-260, 2019, doi: 10.1016/j.procs.2019.05.019.

[12] A. Ma'Arif, H. Nabila, Iswanto, and O. Wahyunggoro, "Application of intelligent search algorithms in proportionalintegral-derivative control of direct-current motor system," $J$. Phys.: Conf. Ser., vol. 1373, 2019, doi: 10.1088/17426596/1373/1/012039.

[13] M. A. Shamseldin and A. A. El-Samahy, "Speed control of BLDC motor by using PID control and self-tuning fuzzy PID controller," in 15th Int. Workshop Research and Education in Mechatronics, 2014, doi: 10.1109/REM.2014.6920443.

[14] K. S. Pawar, M. V. Palwe, S. B. Ellath, and S. Y. Sondkar, "Comparison of performance of PID controller and state feedback controller for flow control loop," in 2018 4th Int. Conf Computing Communication Control and Automation, 2018, doi: 10.1109/ICCUBEA.2018.8697594.

[15] A. Ramelan, J. S. Saputro, C. Hermanu, M. H. Ibrahim, and S. Pramono, "Desain and simulation linear quadratic Gaussian (LQG) for pan-tilt face tracking camera servos," American Institute Physics Conf. Proc., vol. 2217, no. 1, 2020, doi: 10.1063/5.0000614.

[16] N. H. M. Nasir, B. S. K. K. Ibrahim, and M. K. I. Ahmad, "Comparative study on mathematical and black box modelling approaches of musculoskeletal system," in Int. Semin. Appl. Sci. Math., 2011, pp. 1-8.

[17] Ilham, "Kendali kecepatan motor induksi 3 phasa menggunakan linear quadratic regulator (LQR)," Inspiration J. Teknol. Inf. dan Komun., vol. 3, no. 1, pp. 61-68, 2013, doi: 10.35585/inspir.v3i1.33.

[18] M. Swargiary, J. Dey, and T. K. Saha, "Optimal speed control of induction motor based on linear quadratic regulator theory," in 2015 Annu. IEEE India Conf., 2015, doi: 10.1109/INDICON.2015.7443806.

[19] O. S. Ebrahim, M. F. Salem, P. K. Jain, and M. A. A. Badr, "Application of linear quadratic regulator theory to the stator field-oriented control of induction motors," Institution Eng. Technol. Electr. Power Appl., vol. 4, no. 8, pp. 637-646, Sep. 2010, doi: 10.1049/iet-epa.2009.0164.

[20] T. Abut, "Modeling and optimal control of a DC motor," Int. J. Eng. Trends Technol., vol. 32, no. 3, pp. 146-150, 2016, doi: 10.14445/22315381/IJETT-V32P227.

[21] W. M. W. Syahidah, O. Rosli, M. A. Joraimee, and A Norhidayah, "Linear quadratic Gaussian (LQG) controller design for servo motor," Australian J. Basic and Appl. Sci., vol. 8, no. 4, pp. 700-713, 2014.

[22] H. Maghfiroh, C. Hermanu, M. H. Ibrahim, M. Anwar, and A. Ramelan, "Hybrid fuzzy-PID like optimal control to reduce energy consumption," Telecommun. Comput. Electron. and Control, vol. 18, no. 4, pp. 2053-2061, Aug. 2020, doi: 10.12928/TELKOMNIKA.v18i4.14535.

[23] N. K. Roy, H. R. Pota, M. A. Mahmud, and M. J. Hossain, "Voltage control of emerging distribution systems with induction motor loads using robust LQG approach," Int. Trans. Electr. Energy Syst., vol. 24, no. 7, pp. 927-943, 2014, doi: 10.1002/etep. 1739 